\title{
A Method for Optimizing Facades Design for Enhancing Daylight Distribution in Exhibition Spaces
}

\author{
Fatma Fathy ${ }^{1}$, Yasser Mansour ${ }^{1}$, Hanan Sabry ${ }^{1}$, Mostafa Refat $^{1}$, Ayman Wagdy $^{2}$ \\ ${ }^{1}$ Faculty of Engineering, Ain Shams University, Cairo, Egypt \\ ${ }^{2}$ Creative Industries Faculty, Queensland University of Technology (QUT), Brisbane, Australia
}

\begin{abstract}
Daylighting is a challenging architectural aspect that is usually avoided in exhibition spaces. This is due to the high variation over time and being influenced by spatial variations, which may affect exhibits sensible to light. Thus, when introducing daylight in such spaces, there should be a special concern on controlling light entering the space for each hour of the year and its impact on distribution pattern. This paper approaches the above problem through a simulation-based workflow to understand the effect of opening positions on daylight distribution pattern. Then, layout design was correlated to façade opening to optimize their positions according to the recommended lighting annual exposures. Results showed that daylight can contribute to object's illumination by $80 \%$ without exceeding the maximum allowable exposure limit.
\end{abstract}

\section{Introduction}

It is important to provide a well-designed exhibition spaces and controlled environment for the exhibits to protect them from damage. Light is one factor that triggers irreversible damage to the artefacts. This can be caused by all wavelengths of light and the scale of influence depends on the sensitivity of objects and duration of exposure (Kamal et al., 2018). The lighting strategy for exhibitions aims to decrease both light intensity and duration of exposure to light especially for the highly sensitive materials besides, installing high-efficient lighting fixtures.

Preventive conservation policy of any museum should take into account the light sensitivity of the exhibits before setting the adequate light levels. A series of museum lighting guidelines have been published by different authorities where annual photometric exposure limits are given as shown in Table 1 (del Hoyo-Meléndez et al., 2011). The differences in the maximum allowable exposure values return to the number of hours and days per year when the artefacts are assumed to be exposed to light radiation. For example, the IES determine 50 lux the maximum annual exposure based on 8 hours per day over 125 days over the year. Whereas, the CCI recommends it to be 100 lux based on 8 hours per day for 250 days per year.

Daylighting in museums can be accompanied by risks on the artefacts sensible to light, so it is avoided most often and replaced by artificial light which is simpler to apply and control. Taking Tutankhamun galleries in the grand Egyptian museum as an example, daylighting was almost eliminated by a black box gallery where only $2 \%$ of light was allowed which reaches less than 50 Lux inside the gallery. This is well-enough to provide way finding for visitors, whereas at night indirect wall and ceiling lighting will illuminate the gallery with 10-50 lux in addition to remotely controlled lighting in the showcases (Kamal et al., 2018).

Table 1: Summary of recommended annual exposure limits for museum artefacts (del Hoyo-Meléndez et al., 2011).

\begin{tabular}{|l|l|l|l|}
\hline $\begin{array}{l}\text { Recommending } \\
\text { organization }\end{array}$ & $\begin{array}{l}\text { Low } \\
\text { sensitivity } \\
\text { (klx h/y) }\end{array}$ & $\begin{array}{l}\text { Moderate } \\
\text { sensitivity } \\
\text { (klx h/y) }\end{array}$ & $\begin{array}{l}\text { High } \\
\text { sensitivity } \\
\text { (klx h/y) }\end{array}$ \\
\hline $\begin{array}{l}\text { Illuminating } \\
\text { Engineering } \\
\text { Society of North } \\
\text { America (IES) }\end{array}$ & Variable & 480 & 50 \\
\hline $\begin{array}{l}\text { Heritage } \\
\text { Collections } \\
\text { Council, } \\
\text { Australia }\end{array}$ & - & $507-650$ & $127-200$ \\
\hline $\begin{array}{l}\text { Canadian } \\
\text { Conservation } \\
\text { Institute (CCI) }\end{array}$ & - & 1000 (ISO & 100 (ISO 2) \\
\hline
\end{tabular}

There are two arguments regarding this issue; one argues that artificial lights are preferable and the other advocate the integration of daylight with artificial lights (Baker et al., 2013). Both present a good point of view, the former argues that daylight radiation and its variation are the most damaging factors to pigments, textiles and sensitive materials. The characteristics of daylight can be resembled using white artificial lights. Also, daylight systems are more expensive compared to artificial light systems. In addition, avoiding window openings can solve easily the concern of infiltration and dust inside the space. On the other hand, most of the exhibits have been created under the natural light whereas, artificial lights prevent visitors to observe the tiny details of the artwork. Besides, the use of daylight can decrease the costs of artificial light, reduce energy consumption and the negative environmental impacts accompanied with it. And unlike the monotonous artificial light, the variation of daylight is a source of visual interest to the visitors (de Oliveira and Guedes, 2006).

Visual interest is associated directly with luminance variation which is directly related to the distribution of daylight patterns. So, these patterns have a vital role in making architectural spaces more exciting and 
stimulating. Spatial contrast can provide positive visual impressions of the space. This daylight aspect can be measured using annual metrics; Spatial Contrast (SC) and Luminance Variability which are suggested to quantify contrast-based perceptual visual effects (Rockcastle and Andersen, 2014).

Spatial contrast with interesting daylight distribution can be achieved with irregular patterns. Manipulating geometric regularity of facades configurations results in various daylight patterns that influence the perceived spatial ambiance. In (Chamilothori et al., 2016), the effect of façade configurations on perception was examined through an experiment where participants were asked about how pleasant, interesting, and exciting two immersive scenes using virtual reality. Results indicated that irregular pattern gained more positive responses regarding pleasantness, excitement, interest, and complexity compared to regular pattern and blinds. This study was extended to investigate the impact of façade geometry and sunlight patterns on heart rates with an emphasis on the importance of space context on both subjective responses and objective physiological indicators (Chamilothori et al., 2019).

In a space context having cultural or educational setting like exhibition spaces, it is important to capture the interest of the visitors while protecting the exhibits. The quality of exhibits has a major role; however, it is equally important that the architectural space is well designed to stimulate its visitors. From the perspective of daylight, different aspects should be considered for designing a daylit exhibition space; 1) illuminance levels adequate to visualize exhibits but at the same time 2) do not exceed a maximum value to protect the exhibits from damage, 3 ) daylight distribution patterns and spatial contrast based on activity type and layout design, 4) visitor's visual interest and 5) visual comfort.

Pointing to the evaluation of daylight based on its distribution patterns, Caldas and Santos (2016) introduced an interactive system that considers daylight distribution for daylighting design named 'painting with light'. They used evolutionary genetic algorithms to search for solutions that meet the required light levels with the specified spatial coloured pattern of light distribution.

Still, limited attention has been paid to layout design in relation to daylight distribution which is important in spaces like exhibitions, So, this paper aims to analyse the distribution patterns of daylight in relation to facade opening positions. A simulation workflow was proposed to evaluate and optimize openings allocations to ensure meeting the recommended daylight exposure according to the IES while considering spatial contrast. The following section describes the adopted parametric approach which rationed the use of daylight without compromising the condition of the objects.

\section{Methodology}

In this paper, a generic exhibition space located in Cairo was modelled using Rhinoceros software and its parametric platform Grasshopper (Rutten, 2019). The space is assumed to be North oriented so that only diffused daylight can enter the space for 8 hours per day from 10am to $6 \mathrm{pm}$. Space dimensions and materials are illustrated in Table 2. Diva-for Rhino (Solemma, 2019), which interfaces Radiance and Daysim, was used for daylighting simulations. The North façade was divided into a $10 * 6$ square grid of $0.5 * 0.5 \mathrm{~m}$ each square can be used as an opening as shown in Figure 1. Sixty (60) simulations were conducted where each square cell of the façade was given a glazing material while others were kept opaque so that we can understand the effect of each position of the openings on daylight distribution on all interior surfaces. Eight analysis grids were used to capture the illuminance distribution inside the space which includes 6 grids parallel to the internal surfaces of the room (floor, roof, and the 4 walls) besides horizontal grid at $70 \mathrm{~cm}$, and vertical grid facing the main façade looking to outside.
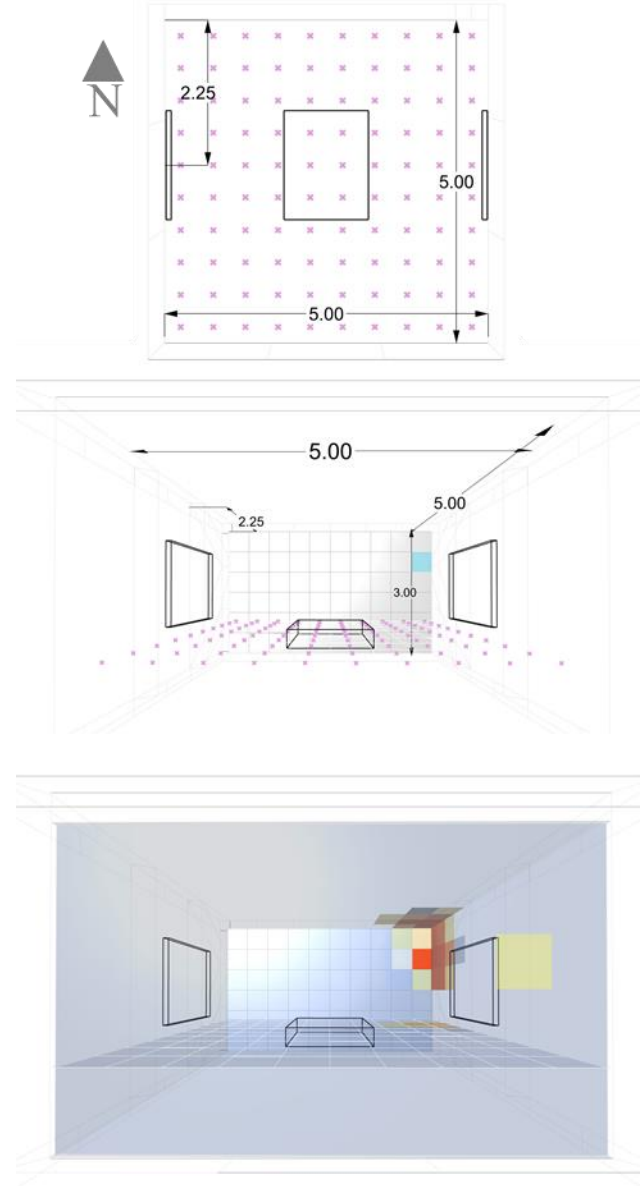

Figure 1: Space Layout and Façade Openings.

The space encompassed three objects; a show case in the centre of the space precisely to be $2.25 \mathrm{~m}$ far from the main facade, and two painting on the side walls aligned with the showcase as shown in Figure1. The simulation process comprised of three consecutive steps. First, identifying the optimal opening positions based on layout design. Second, optimising their size to rationing daylight entrance. Third, selecting the duration of exposure to make the best use of daylight and minimize artificial lights 
Table 2: Space Parameters and Materials.

\begin{tabular}{|c|c|c|}
\hline \multirow{3}{*}{$\begin{array}{l}\mathscr{E} \\
\text { के } \\
\text { की }\end{array}$} & Floor Level & Ground Floor \\
\hline & Space dimensions & $5.00 * 5.00 \mathrm{~m}$ \\
\hline & Height & $3.00 \mathrm{~m}$ \\
\hline \multirow{4}{*}{ 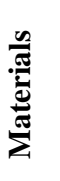 } & Ceiling reflectance & $80 \%$ \\
\hline & Walls reflectance & $50 \%$ \\
\hline & Floor reflectance & $20 \%$ \\
\hline & Double pane Glazing Transmittance & $80 \%$ \\
\hline
\end{tabular}

\section{Phase One: Identifying Opening Positions}

Based on layout design of the space, six sensors were intersected with the showcase position. Average illuminance at these sensors was calculated for each façade configuration. A weighting factor was given to each opening position indicating its contribution to the amount of daylight incident on the showcase. This weighting factor denotes the average Continuous Daylight Autonomy ( $\left.\mathrm{DA}_{\text {con }}\right)$ of the intersecting sensors with the showcase. This daylight metric was used as it gives partial counts for illuminance levels below the threshold (Reinhart et al., 2006), which was set in this study to be 50 Lux.

Then, the opening positions were sorted based on $\mathrm{DA}_{\text {con }}$ values. The configuration which corresponded to the highest $\mathrm{DA}_{\text {con }}$ was selected to be the main source of light for the showcase. It represented the optimal position for highlighting the showcase compared to other configurations. This process was repeated for the two paintings hanging on the wall. So, three opening positions were selected for each object.

\section{Phase Two: Optimising Openings scale}

After setting opening positions, the second phase was concerned with optimizing their size aiming to maximize daylight while keeping illuminance levels below 50 Lux. Scale ratio of the three openings was varied from 1 to 0.5 with increment 0.1 forming $6^{3}$ variations to represent 216 different configurations. The performance of these configurations was evaluated based on illuminance incident on the three objects. First, they were sorted according to the average illuminance, calculated on sensors intersected with the three objects, to choose the highest average value while maintaining at the same time the maximum illuminance at any point in time to be below 50 Lux. In this phase, daylight illuminance was maximized. However, 50 Lux was not achieved totally by daylight, so it should always be compensated by dimmable artificial light for certain hours to reach 50 Lux at each hour of the day.

\section{Phase Three: Optimizing Duration of Exposure}

According to the IES, the duration of exposure is 8 hours per day for 125 days per year resulting in $1000 \mathrm{hrs}$ to reach the recommended 50klux h/year. In this phase, it is aimed to reach the required exposure, $\left(\mathrm{H}_{\mathrm{T}}\right)$ in lux hours, so that it would not exceed the maximum allowable limit of 50klux/year at the three located objects. The duration of daylight exposure was aimed to be maximized as much as possible to reduce the use of artificial light. Accordingly, the 125 days of the year were proposed to be chosen for the four months in the year when daylight use is higher than the artificial for the three objects location. So, illuminance contribution of daylight was calculated and compared against that of artificial for the 8 hours of the day along all months of the year.

\section{Results}

\section{Phase one:}

Each opening position has an index from 0 to 59 starting from the bottom right corner to the upper left corner. Results of the sixty positions were sorted three times according to the average Continuous Daylight Autonomy $\left(\mathrm{DA}_{\mathrm{con}}\right)$ on the painting on West wall, show case, and the painting on East wall. For the West wall painting, indices 46 and 47 were found to have highest weighting factor; $71 \%$, and $70 \%$ respectively representing the best opening positions of illuminating the painting. Both positions were at $2.25 \mathrm{~m}$ high from the ground and 1.75 and $1.25 \mathrm{~m}$ far from the West wall. For the showcase, position index 34 was found to have the highest weighting factor of $74 \%$. It is located in the centre of the façade at a height $1.75 \mathrm{~m}$ from the ground. As for the East painting, indices 43 and
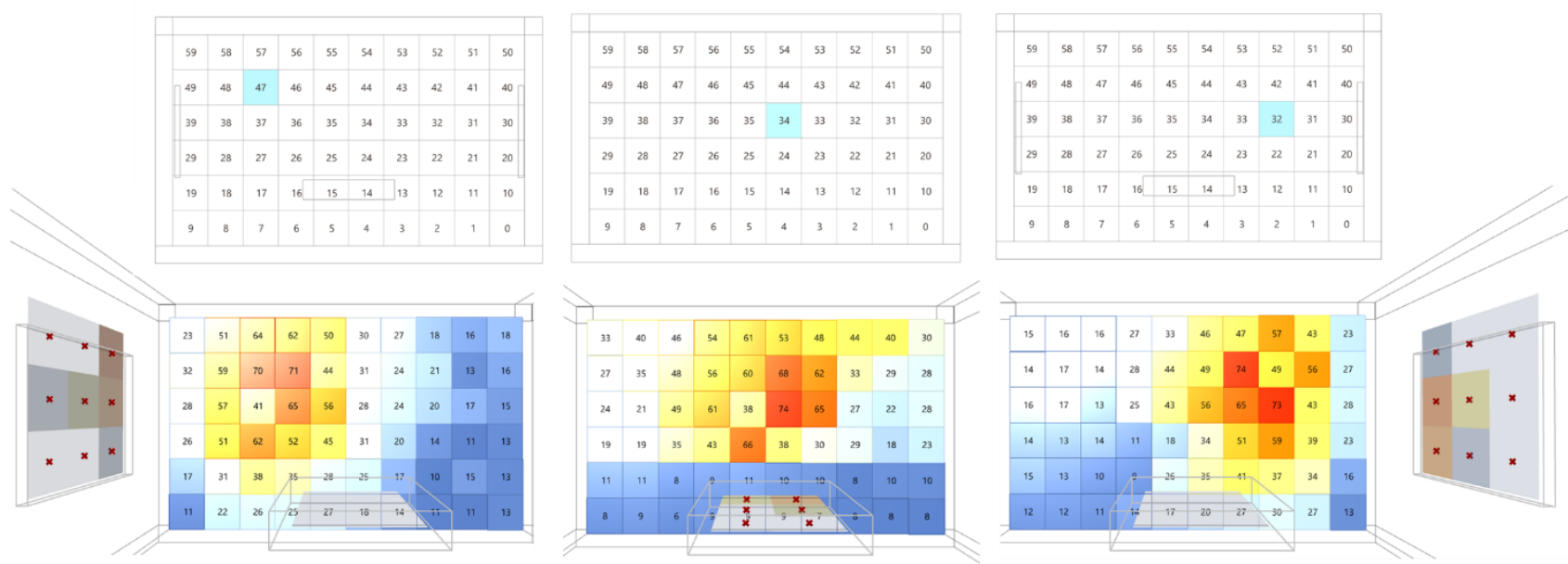

Figure 2: Indices of opening positions and their weighting factors corresponding to the average DAcont on a) West Painting, b) Showcase, and c) East Painting. 
32 were found to have the largest illumination impact of $74 \%$ and $73 \%$ respectively. They are in the right side of the façade $1.75 \mathrm{~m}$ and $1.25 \mathrm{~m}$ far from the East edge and $2.25 \mathrm{~m}$ and $1.75 \mathrm{~m}$ high from the ground. Intending to realize spatial contrast inside the space, the three openings were chosen to be apart from each other as much as possible. Thus, indices 47,34 , and 32 were chosen to be the best to highlight the three objects mounted inside the exhibition space as shown in Figure 2.

\section{Phase two:}

Then, to make sure that illuminance levels do not exceed 50 Lux on the three objects, which are assumed to be highly sensitive to light, openings scale were optimized. All possible combinations of the scale size formed 216 different configurations. Hourly illuminance for all combinations were simulated. Then, average illuminance at the three objects grids was calculated which ranged from 4 Lux at the smallest opening scales $0.5,0.5$, and 0.5 to $70 \mathrm{Lux}$ at largest opening scales 1,1 and 1 . After sorting the configurations according to their average illuminance, configuration number 68 with openings scale $0.8,0.5$, and 0.9 as shown in Figure 3 was found to have the highest average illuminance 29 Lux without exceeding 50 Lux at any point in time.

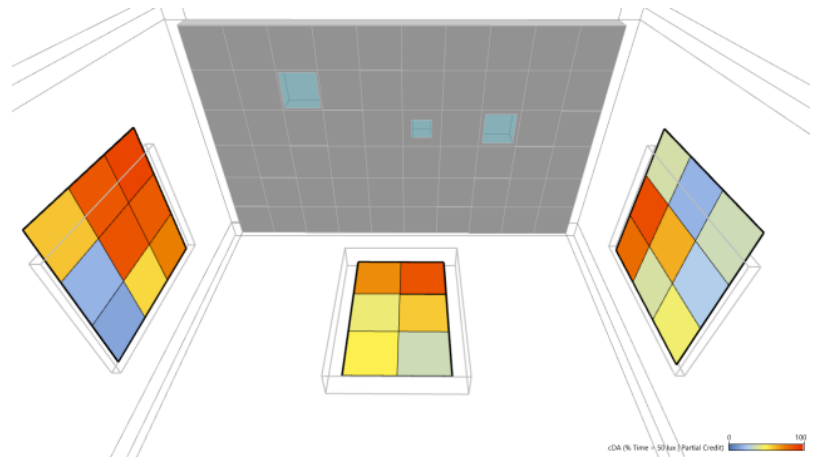

Figure 3: Optimized Openings scale.

\section{Phase Three:}

After ensuring that daylight illuminance did not exceed 50 Lux, artificial light should be considered which complements the deficiency of daylight at certain times of the day. Assuming that the artificial system mounted is dimmable with sensors, 50 Lux will be maintained for the 8 hours of the day. It is equally important to identify the time of exposure as to control the illuminance falling on the objects. By comparing the contribution of daylight and artificial light in illuminating the objects, it was found that best time for exhibiting is from May to August as the daylight contributes with $61 \%, 74 \%$ and $80 \%$ for illuminanting the three objects respectively

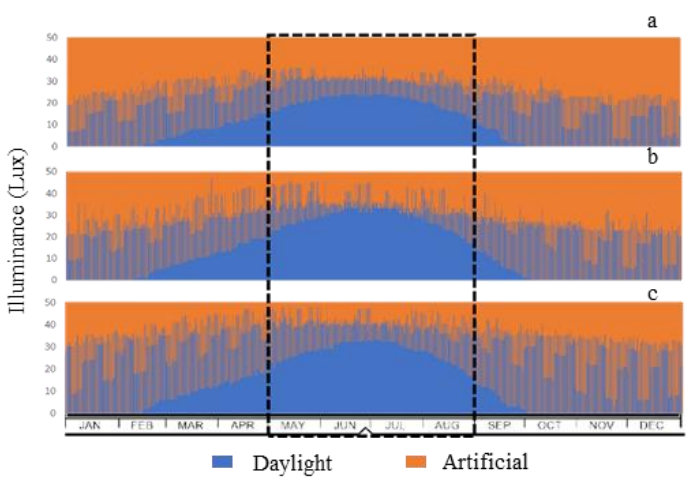

Figure 4: Illuminance caused by daylight and artificial light for a) West painting, b) Showcase, c) East painting.

\section{Discussion}

Daylight has spectral power distribution that provides a better colour rendering than artificial lights, so it contributes to the interpretation of the museum collection and visually enriches their display. It also can contribute to energy efficiency by reducing artificial lighting consumption and the negative impacts associated with it; $\mathrm{CO} 2$ emissions in addition to its positive impact on people wellbeing. On the other hand, intensity control and spatial limitation of daylight are considered two main challenges of daylighting design that hinders its use in museums. This is especially when direct sunlight is accompanied. It is also important to consider the illumination requirements for each object and minimizes the exposure to light to prolong their lifetime. Another limitation is that daylight metrics are confined to providing benchmarks that represent the overall performance of the space without much consideration to the distribution of light spatial pattern which is an important evaluation aspect. So, in this study, a North-oriented exhibition space in Cairo was chosen as a case study to define a method for controlling daylight distribution so that the benefits of daylight can be exploited rather than eliminating its use. Daylight controlling factors used in this study were: 1) positioning of objects inside the space, 2) maximizing illuminance levels on objects while keeping the limit of 50 Lux, as objects type were assumed to be highly sensitive to light, 3) minimizing the dependency on artificial lights.

First, the study addressed the positioning of façade openings; the façade was divided into sixty square cells. All positions were simulated to demonstrate their effect on all interior surfaces with a concentration on the three surfaces were objects are located in. Figure 5 shows the distribution for random configurations. Optimal opening positions were selected to focus the light on objects inside the space and endow spatial contrast. Thus, openings were designed to be small while considering not to be close to each other. Then, the selected openings sizes were optimized to get the highest average illuminance on the objects while keeping the limit below 50Lux for all hours of the year. At last, the exposure period was chosen to be within the summer months to rely more on daylight for the illumination of objects. The proposed simulation method supports more energy efficient spaces. The main 
aim was to rely more on daylight than on artificial light while giving it more control to highlight the objects and draw more attention to them by making contrast with daylight.

\section{Conclusion}

Daylight is a key factor for users' environmental comfort. The architect's role is important to decide on the effective integration of daylighting systems for a better environment. In this way, comfortable and efficient visual conditions can be created while minimizing the negative effects. Although daylight is characterized by high variations along the day and year, this study provides a method to understand these variations and control it through façade design. The allocation of façade openings and the resulting daylight distribution is a defining element in perceiving the space and objects inside. Its optimisation can enhance the quality of space through providing more daylight and reducing artificial light dependency which reached only $20 \%$ when the exposure duration was correctly selected between May and August to maximize the use of daylight against artificial light.

The suggested parametric workflow can be replicated for other orientations and locations by following the three mentioned phases of optimization. In this specific case where only diffused light enter the space, some conclusions can be drawn and generalized. The layout design of the exhibition space plays a vital role in the façade configuration, so it should be considered from the early start. There are no specific benchmarks for evaluating the distribution of daylight can be found aside from uniformity which is not the issue in a space like exhibitions. On the other hand, contrast can be more favoured as it was proven from literature that it increases visual interest. So, for endowing more excitement in the space, it is recommended to apply small openings on certain locations forming random daylight pattern to highlight objects in the space. According to the distribution analysis of this case study, objects are better to be located not more than $2.5 \mathrm{~m}$ far from the façade to get more affected by daylight so, in case of large exhibitions spaces, skylights is a better alternative for introducing effective daylight.

Future work aims to apply a human centric design approach seeking to regard perceptual qualities of light by quantifying luminance variation and correlating it with users' visual subjective perception of the exhibition space. Applying this approach will be used to assess the integration of daylight against the use of merely artificial lights from the visitor's point of view. Acquired data will give more insight to enhance our proposed method and how the collected data can be integrated into the simulation workflow. Also, to understand how facades characteristics and daylight distribution impact users' experience of the exhibition space.

Real measurements are needed in future research to validate the method and ensure the accuracy of results. Also, a correction factor might be deduced to come closer to the physical measurements.

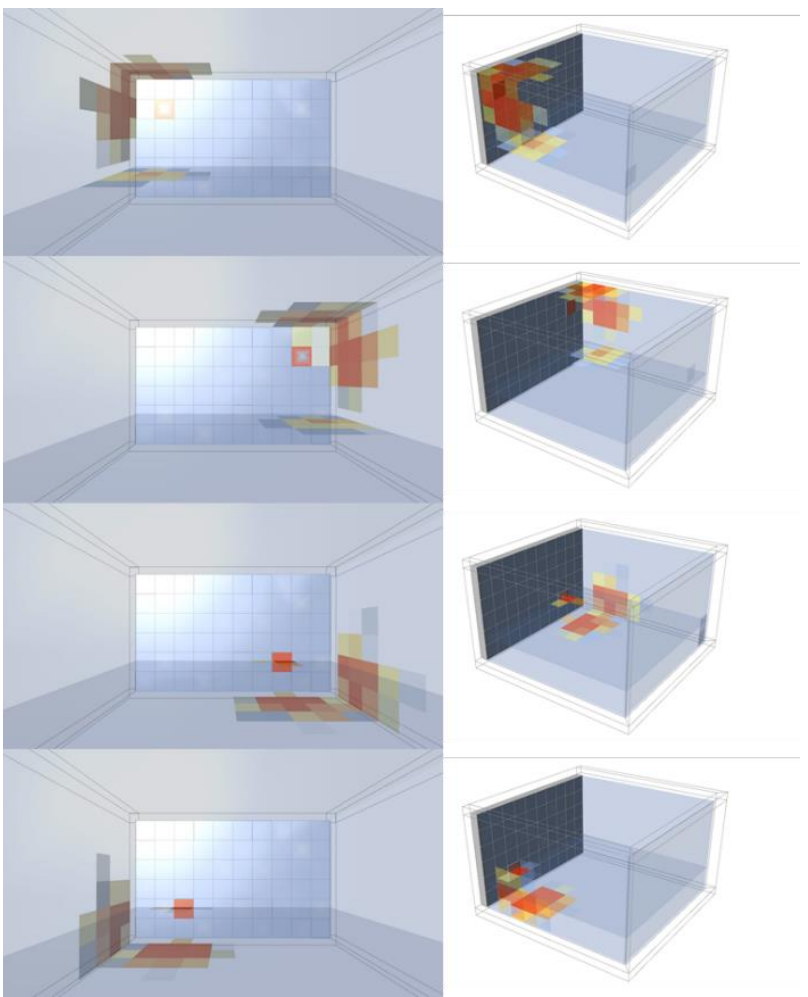

Figure 5: Distribution of daylight of random configurations.

\section{References}

Baker, N. V., Fanchiotti, A. \& Steemers, K. (2013). Daylighting in architecture: a European reference book, Routledge.

Caldas, L. \& Santos, L. 2016. Painting with light: An interactive evolutionary system for daylighting design. Building and Environment, 109, 154-174.

Chamilothori, K., Chinazzo, G., Rodrigues, J., DanGlauser, E., Wienold, J. \& Andersen, M. 2019. Subjective and physiological responses to façade and sunlight pattern geometry in virtual reality. Building and Environment.

Chamilothori, K., Wienold, J. \& Andersen, M. (2016) Published. Daylight patterns as a means to influence the spatial ambience: a preliminary study. Ambiances, tomorrow. Proceedings of 3rd International Congress on Ambiances. Septembre 2016, Volos, Greece, 2016. International Network Ambiances; University of Thessaly, p. 117-122.

de Oliveira, F. S. \& Guedes, M. C. (2006). Daylighting museums-a case study in Lisbon. PLEA2006 - The 23rd Conference on Passive and Low Energy Architecture, 2006 Geneva, Switzerland.

del Hoyo-Meléndez, J. M., Mecklenburg, M. F. \& Doménech-Carbó, M. T. 2011. An evaluation of daylight distribution as an initial preventive conservation measure at two Smithsonian Institution Museums, Washington DC, USA. Journal of Cultural Heritage, 12, 54-64.

Kamal, H. M., Elkhial, M. M. \& Tawfik, T. S. 2018. The Role of Preventive Conservation in Designing King 
Tutankhamun Galleries in the Grand Egyptian Museum. Studies in Conservation, 63, 138-145.

Reinhart, C. F., Mardaljevic, J. \& Rogers, Z. 2006. Dynamic Daylight Performance Metrics for Sustainable Building Design.

Rockcastle, S. \& Andersen, M. 2014. Measuring the dynamics of contrast \& daylight variability in architecture: A proof-of-concept methodology. Building and Environment, 81, 320-333.

Rutten, D. 2019. Grasshopper-Algorithmic modeling for Rhino software version 1.0.0007 [Online]. [Accessed 20-1-2019.

Solemma, L. 2019. DIVA-for-Rhino software version 4.0 [Online]. URL http://www.diva4rhino.com [Accessed 20-1-2019. 